\title{
LA ESTRUCTURA DE PODER POLÍTICO REGIONAL EN EL ECUADOR UN ESTUDIO A PARTIR DE LA ÉLITE POLÍTICA DE LA PROVINCIA DE LOJA $^{1}$
}

William Dario Chará Ordónęz.

\begin{abstract}
Resumen:
En este artículo se aborda la configuración de la estructura de poder político regional de la Provincia de Loja entre 1984 y 2013, luego que la Reforma Agraria y el proceso de modernización estatal del Ecuador. En 1979 modificaran la vieja estructura política que se basó en la hacienda como sistema de dominación bajo la diada Partido Conservador-Iglesia católica. Debido a estas modificaciones, la estructura de poder político inicia un proceso de reacomodo de fuerzas políticas (campesinos, izquierda y agrupaciones disidentes de Partido Conservador) en una competencia por acceder a los escaños para Asamblea Nacional. El estudio de la configuración del sistema de dominación de la hacienda, el papel del Partido Conservador y las nuevas agrupaciones políticas, serán fundamentales para entender cómo los personajes políticos, a partir de sus trayectorias, permiten comprender el papel de la élite política en la toma de decisiones, el ejercicio electoral y el acceso al poder.
\end{abstract}

Palabras-clave: Poder político regional. Élite política, elecciones. Reformas institucionales. Loja.

\section{Resumo:}

Este artigo descreve a configuração da estrutura do poder político regional da província de Loja, entre 1984 e 2013, depois da reforma agrária e do processo de modernização do Estado do Equador. Em 1979, altera-se a estrutura política que foi baseada no campo como sistema de dominação sob a díade Partido Conservador- Igreja Católica. Devido a essas alterações, a estrutura do poder político iniciou um processo de realinhamento de forças políticas (camponeses, grupos de esquerda e dissidentes do Partido Conservador) em uma competição pelo acesso aos assentos da Assembleia Nacional. O estudo da configuração do sistema de dominação fazendária, o papel do Partido Conservador e os novos grupos políticos serão essenciais para entender o papel da elite política e figuras políticas, a partir de suas trajetórias, na tomada de decisão, no exercício eleitoral e acesso ao poder.

Palavras-chave: poder político regional; elite política; eleições; reformas institucionais; Loja (Equador).

\footnotetext{
${ }^{1}$ Este breve artículo, es realizado en el marco de la tesis denominada Estructura de poder político regional en el Ecuador. El estudio de caso corresponde a la Provincia de Loja, ubicada en la región sur de la República del Ecuador, límite con la República de Perú. Su importancia radical en la fuerte presencia de una economía colonial, el florecimiento de las artes liberales nacionales y el rezago económico y político que ha soportado durante el siglo XX. Esta investigación no hubiese sido posible sin la participación de personas muy cercanas. Por tanto, agradezco las asesorías del Ph.D. Alexander Montoya Prada; Ph,D. Valeria Coronel; Mg. Lorena Flórez; Mg. José Nicolás López; Mg. Gildardo Vanegas y Mg. Alexander Castillo. De igual manera a Mg. Liz Lema y Astrid Méndez por el constante apoyo, la lectura y el acompañamiento.

${ }^{2}$ Politólogo (Universidad del Cauca - Colombia), maestro en Sociología (Facultad Latinoamericana de Ciencias Sociales - sede Ecuador). Investigador de estudios sobre conflicto, partidos políticos, comportamiento electoral, y, recientemente, élites políticas regionales. Dirección de correo electrónico: williamchara@unicauca.edu.co - williamchara@hotmail.com
} 


\section{Abstract:}

This article describes the configuration of the regional structure of political power in the province of Loja, between 1984 and 2013, after the agrarian reform and modernization of the State of Ecuador process. In 1979, amendments to policy structure that was based on the field as the system of domination in the Catholic Church-Conservative Party dyad. Because of these changes, the structure of political power has begun a process of realignment of political forces (peasants, leftists and dissidents of the Conservative Party) in competition for access to the seats of the National Assembly. The study of the treasury domination system configuration, the role of the Conservative Party and the new political groups will be essential to understand the role of the political elite and political figures from their trajectories in decision making, in the electoral exercise and access to power.

Key-words: regional political power; political elite; elections; institutional reforms; Loja (Ecuador).

\section{A MANERA DE INTRODUCCIÓN}

En este artículo se aborda la configuración de la estructura de poder político regional de la Provincia de Loja entre 1984 y 2013, luego que la Reforma Agraria y el proceso de modernización estatal del Ecuador en 1979 modificaran la vieja estructura política que se basó en la hacienda como sistema de dominación bajo la diada Partido Conservador-Iglesia católica. Debido a estas modificaciones, la estructura de poder político inicia un proceso de reacomodo de fuerzas políticas (campesinos, izquierda y agrupaciones disidentes de Partido Conservador) en una competencia por acceder a los escaños para Asamblea Nacional. El estudio de la configuración del sistema de dominación de la hacienda, el papel del Partido Conservador y las nuevas agrupaciones políticas, serán fundamentales para entender cómo los personajes políticos, a partir de sus trayectorias, permiten comprender el papel de la élite política en la toma de decisiones, el ejercicio electoral y el acceso al poder.

\section{EL REFERENTE CONCEPTUAL DEL ESTUDIO DE LA ESTRUCTURA DE PODER POLÍTICO REGIONAL}

A partir del libro The Political System. An Inquiry into the State of Political Science de David Easton, el análisis de la política poco ha podido separarse de la idea de entender el funcionamiento de los actores políticos. Sin duda, dentro de los actores institucionalizados, los políticos y las élites políticas resultan ser importantes toda vez que, en democracias contemporáneas, los representantes de la política son quienes tomas decisiones. En este sentido, la discusión conceptual que se adelanta es un tema que ha sido menester de la Sociología y, más recientemente de la Ciencia Política, y que parte de la necesidad de ahondar en el análisis de los estudios sobre poder político más allá de los límites disciplinarios profundamente interiorizados sobre el tema y que se agotan en el supuesto 
que insiste en igualar al poder político con la dominación. Así, nos adentramos a una discusión que pretende caracterizar qué implica tal dominación, qué redes se tejen en ese proceso, quiénes realizan este oficio y cómo se segura el poder.

Un elemento central en el estudio del poder político es la relación del poder con la dominación. Siguiendo a Weber se entiende por dominación como un agregado de factores "por el cual una voluntad manifiesta del dominador o de los dominadores influye sobre los actos del dominado o dominados de tal suerte que en un grado socialmente relevante estos actores tienen lugar como si los dominados hubieran adoptado por sí mismos y como máxima de su obrar el contenido del mandato" (WEBER, 1977: 699). Con esta definición de dominación, planteamos la idea que la configuración del poder político resulta de una relación desigual y está relacionada con lo que Weber llamó el régimen de gobierno ya que "toda dominación se manifiesta y funciona en forma de gobierno. Todo régimen, necesita del dominio en alguna forma pues para su desempeño siempre se deben colocar en manos de algunos poderes imperantes" (WEBER, 1977: 701). En ese sentido, se identifica al poder político como una consecuencia del ejercicio de funciones políticas las cuales están cimentadas en una minoría, una clase que lo determina.

El poder político como una condición de dominación, tiene actores que se lo disputan. Caracterizar quienes son, y cómo llamar a estos actores ha sido un amplio debate de las ciencias sociales, en específico de la Sociología y la Ciencia Política. ${ }^{3}$ Ambas, se han debatido entre el concepto más adecuado de nombrar al grupo que detenta el poder y cuáles son las condiciones que llevan a ser a un grupo, el dominante. La primera de ellas es caracterizar este grupo como una élite política. Siguiendo a Wrigth Mills tras estudiar este grupo en Estados Unidos, encontró que la clave estructural de la élite del poder reside en el sector político (MILLS, 1957: 256). El segundo de los estudios que busca caracterizar a este grupo está orientado por Gaetano Mosca, quien argumenta que la élite del poder no asegura solamente su posición dentro de una estructura de poder a partir de condiciones económicas o políticas producto del fortalecimiento militar. El carácter de la herencia del poder es un factor importante que caracteriza a la clase política. Para Mosca "todas las clases políticas tienden a volverse hereditarias, si no de derecho, al menos de hecho. Ello es, la tendencia a permanecer en el punto y en el estado en el que se encuentran" (MOSCA, 1984: 31). Haciendo uso de lo planteado, a este grupo lo denominaremos élite política, incluyendo así la condición de clase política y de élite en el poder. Esta élite política, por

${ }^{3}$ Con el propósito de buscar una mirada desde los actores mismos y sus percepciones frente a la Democracia se formula el PELA (Proyecto Élites Parlamentarias Latinoamericanas). 
medio del control de las relaciones políticas, las económicas y sociales determina la manera como se configura una estructura de poder en una región.

Para hablar de una definición de lo político hay que exponer éste concepto que gira en torno al debate entre dos concepciones: la acción política y la naturaleza del trabajo político. La primera, es aquella que determina a un político como aquel que hace política, que interviene en ésta, hace parte de la toma de decisiones e intenta transformar la realidad de su entorno social. La segunda, es quizá la que entiende por político a aquel que tiene una identidad política, la cual se a partir de su identificación moral sin tener que hacer parte de una etiqueta partidista. Ambas concepciones son entendidas por la idea de Weber de la política como profesión o como vocación. Según Alcántara (2006) es deber del estudioso hacer esta definición. Weber en su trabajo formuló una distinción entre políticos profesionales, políticos semiprofesionales y políticos ocasionales. Ello, bajo la necesidad desde el siglo XIX de caracterizar a las personas que se ocupaban del trabajo legislativo, en donde existían profesionales, profesores e intelectuales.

Weber al identificar las categorías de la acción política permitió caracterizar el quehacer de los políticos. ${ }^{4}$ Se puede decir de los políticos profesionales, siguiendo a Weber, que son aquellos que viven de la política y cuya dedicación a la política es de tiempo completo y su vida está al servicio de la política. Así, como político profesional se identifica a aquellos que viven de la política y tienen, por generalidad, un pago por ello. A partir de esta premisa, se puede seguir con la identificación de la élite política a partir de la tipología realizada por Panebianco (1982); la tipología de político profesional realizada por Sartori (1992:178), el trabajo en Italia e Inglaterra sobre características de las élites de Putnam (1976) y la tipología de $\mathrm{Salb}^{5}$ (2002) que se centra en los requisitos asociados a las distintas actividades políticas.

De esta manera, se puede afirmar que un político, no sólo por la actividad concreta en el quehacer político sino en la manera como accede a ella, es un actor que se ubica en alguna de las cuatro arenas siguientes: cargos de elección popular; altos cargos de libre designación o de confianza de la administración del Estado o entidades o autónomas;

${ }^{4}$ Los políticos ocasionales, son aquellos individuos que se consideran como políticos al depositar su voto en una urna hasta los que realizan manifestaciones de voluntad por algún tema de incidencia personal o colectiva. Los políticos semiprofesionales, son aquellos que desempeñan labores políticas sin vivir de ello exclusivamente. La política, para éstos, no es más que una de las tantas acciones a realizar.

5Para Salb, hay tres tipos de oficios políticos. El primero es el político electo por votación, seguido de aquel que es el motivador, el activista político y el tercero es el trabajador político mucho más local, más de la comunidad. Ver (Alcántara, 2012). Esta tipología no es excluyente, aunque un político profesional puede, sea el caso, pasar por estos momentos. 
puestos de responsabilidad orgánica y de asesoría en el seno de los partidos políticos; y, por último, quienes habiendo estado en una de las tres situaciones recién descritas continúan ejerciendo influencia mediante un "efecto sombra" por su prestigio pretérito. (ALCÁNTARA, 2006:83).

Una tipología más próxima al contexto de América Latina, ${ }^{6}$ en especial de los países de la zona andina, distingue a cuatro tipos de políticos profesionales, que sin vivir específicamente de la política, ven en ella la mejor de las opciones tanto para el accionar de la política en estricto sentido y el desarrollo de sus propias vidas y necesidades. Siguiendo los trabajos de Almond y Verba (1991), Rojas (1991), Leal Buitrago (1991), Roll (1999), Ortiz (1986), se puede observar que la estructura del poder político es, eminentemente, un proceso de dominación que depende de una minoría política que detente el poder, que cohesione las demandas y las transmite al sistema político para garantizar su permanencia en el escenario político. Si bien, la permanencia puede estar asegurada por principios de herencia o transmisión de cargos, producto de la poca movilidad en las esferas de representación política, existe una estructura que presupone la existencia de un líder o un grupo líder que mantenga las condiciones para asegurarse al control del poder. Dentro de la élite política regional, se encuentran cuatro niveles con los que identifican los actores. En el primero está el jefe regional. En el segundo, los dirigentes regionales que controlan las subregiones. En tercer lugar, los empleados públicos que representan una parte importante de los empleados y, finalmente, los trabajadores políticos locales (DÍAZ, 1986:20). En el Ecuador, puede leerse esta composición de la élite política, espacialmente en una región como la provincia de Loja.

\section{EL CONTEXTO DE LA ESTRUCTURA DE PODER POLÍTICO REGIONAL LOS INICIOS DEL SIGLO XX}

El inicio del siglo XX en el Ecuador se enmarca en la puesta en marcha de la Revolución Liberal. El primer intento de transformación estatal que incluyó una propuesta de liberalización de la sociedad, la economía y la política de la vieja estructura republicana. A nivel provincial, el proyecto de modernización del Estado presentó tres elementos

\footnotetext{
${ }^{6}$ Entre los estudios realizados para el cono sur de Latinoamérica el tema resaltan: Lodola (2009) identificando la estructura subnacional de las carreras políticas en Brasil y Argentina; y Almaraz (2010) con un estudio regional de políticos profesionales en Argentina.
} 
fundamentales: 1) la constitución de un aparato local del Estado muy embrionario hasta la fecha. 2) el control del personal político local escogido desde entonces en las filas de los liberales lojanos y 3) el control del proceso electoral hasta entonces totalmente abandonando a la fracción conservadora de la clase terrateniente. A principios del siglo $\mathrm{XX}$, el poder central del Ecuador intervino en estas propuestas, impidiendo que las dos últimas se realizaran. De ahí, que la política y las elecciones estuvieran fuertemente dominadas por la burguesía terrateniente.

Los avances de la Revolución Liberal mantienen una posición de socavar las bases del poder terrateniente. Si bien, el Estado Ecuatoriano mantiene durante las primeras décadas del siglo XX una lenta expansión del control del territorio, a nivel regional "el Estado aparecía cada día más como un árbitro entre los diferentes intereses particulares, interviniendo a veces en forma directa en los asuntos locales. (FAUROUX, 1983: 241). Sin duda, el Estado ecuatoriano de principios del siglo XX, que se debate entre un modelo de centralismo político, pretende mantener una vinculación más eficiente con las provincias más relegadas del ámbito político y económico.

La élite terrateniente: El Partido Conservador, la Iglesia Católica y La hacienda como sistema de dominación (1930-1979)

La élite terrateniente lojana se consolida a partir de la hacienda tradicional, la cual "se asentó sobre una base más amplia: por lo precario de su condición socioeconómica, la mano de obra se encontró más dependiente, arrinconada a aceptar condiciones de explotación más drásticas" (FAUROUX, 1983:240). A finales del siglo XIX, "las bases económicas del poder de los terratenientes lojanos son particularmente fuertes. Por una parte, "se apoyaban en un monopolio casi completo de la tierra y una organización sociopolítica sumamente eficaz en el control del trabajo" (FAUROUX, 1983:242). Por otra parte, existe un gran poder político, social y económico de "un grupo social, o para decirlo en rigor, de una familia puesto que los apellidos Burneo, Valdivieso y Eguiguren se hayan fuertemente entrelazados, al tiempo que se unen a ella otros sectores latifundistas" (GALARZA, 1976: 255).

Con la hacienda y su sistema de dominación, el papel de la Iglesia católica sería fundamental como control social. Su poder, desde la colonia, fue importante en la región de Loja para "la pacificación de los pueblos guerreros de Loja y Piura, la necesidad de encuadrar ideológicamente a la población nativa para el pago de tributos y el cumplimiento de las mitas" (RAMÓN, 1983:90). Con el advenimiento de la hacienda, la Iglesia sería una 
importante institución terrateniente que ligaría el pago de tributos al control y servicio de la religión. ${ }^{7}$

La hacienda y la Iglesia católica se complementan como sistema de dominación tras un débil Estado colonial desentendido de la región sur del Ecuador. Políticamente, es el Partido Conservador quien utiliza la débil institucionalidad pública como mecanismo de cohesión social tras proclamarse como el único sobre los que recae la responsabilidad de integración y de progreso de la provincia. Con ello, cualquier iniciativa desde algunos sectores organizados de campesinos o comerciantes son suprimidos por los conservadores que cuestionan la decisión de asociación por fuera del partido a partir del "carácter patriótico que se basa en la necesidad de controlar la presión de poder central y controlar el poder de cualquier iniciativa proveniente de otros sectores" (RAMÓN, 1983: 87). Tanto curas como hacendados se mueven por la región llevando un discurso religioso y moral como pretexto para conocer la existencia de casos de organización y luego reprimirlos. Así, entre votos, apertura de caminos y misiones evangelizadoras se realiza la política electoral regional.

De esta manera, la élite política mantiene a los campesinos cohesionados y logra atraer a los sectores medios con el ofrecimiento de cargos burocráticos o nombramientos en instituciones oficiales, especialmente en las alcaldías y colegios fiscales. Con una economía basada en la agricultura, el poco comercio y las precarias alternativas económicas, un empleo público resultaba ser la mejor manera de vida para la clase media en pleno ascenso (Lecoq, 1986:76). Los mecanismos económicos de la hacienda, el sentimiento de reivindicación del atraso y el abandono, la falta de gestión pública, el impedimento a la asociación de sectores sociales y el dominio ideológico de la Iglesia católica fueron la base con la que el Partido Conservador se hizo al poder en la región de Loja hasta entrada la década de 1970.

El fin de la hegemonía conservadora, la eliminación de la hacienda como sistema de dominación y las transformaciones en la politica regional (1965-1978)

Con el fin del proyecto de la Revolución Liberal en Ecuador, la provincia de Loja experimenta un proceso de reacomodo de las fuerzas productivas y de la lógica de poder.

${ }^{7}$ Puede verse en Galo Ramón (1983: 83-85) y Jaramillo (1974:74-92), la relación entre economía y religiosidad con el temprano culto a la Virgen del Cisne y el papel de ésta como símbolo de necesidad y veneración agrícola. 
La hacienda y su estructura de dominación inician un proceso de eliminación gradual que se expresaría en la más dura crisis, llevándola a su abolición. La Reforma Agraria ${ }^{8}$ propuesta en 1964 y puesta en marcha a partir de 1968, tiene entre sus principales antecedentes las movilizaciones y paros campesinos por mejores condiciones de vida desde finales de la década de 1930 y las fuertes sequías que azotaron la región entre los años 1964 y 1966.

Con la Reforma Agraria, la entrega y venta de tierras terminaron por sentenciar el dominio terrateniente. Ello, no significó que el nuevo escenario de la Reforma generara una nueva manera de control del poder, pues esta élite terrateniente nunca tuvo un proyecto hegemónico que propiciara por mejorar las condiciones de la provincia. "Mientras que los exhacendados incursionaron en la producción agropecuaria a través de la conformación de sólidas empresas, inclusive agroindustrias altamente calificadas, en la provincia de Loja tal fenómeno no se presentó". (GUERRERO, 2005:57). El dinero recibido por la venta de tierras, sumado al acumulado por el sistema hacendatario, no fue utilizado para la inversión en la economía regional, por el contrario, se concentró en fortalecer el pequeño comercio nacional o salió del territorio.

Debido a la coyuntura, las agrupaciones de izquierda, la élite intelectual lojana y las organizaciones sociales, mayoritariamente universitarias, atizaron el fuego del descontento campesino y popular urbano, convencidos de que las condiciones objetivas de la revolución estaban dadas. Alrededor de este proyecto político, se armó un entramado administrativo y logístico que puso en jaque a las élites provinciales, especialmente a los terratenientes. La distribución y entrada de la tierra se realizó entre 1968 y 1980. Sin embargo, la tierra que fue entregada a la Reforma no fue la mejor. Los terratenientes buscaron quedarse con la tierra más productiva. Esta tierra, tendría mayor capacidad de venta, y la que no se vendió, se ocupó exclusivamente a la ganadería, actividad que por no necesitar de mano de obra extensiva y contar con un mercado menos especulativo, resultaba una rentable actividad económica. Sin duda, con la Reforma Agraria, el sistema de dominación de la hacienda, habría llegado a su fin

El dominio de los terratenientes se mantendría hasta finales de la década de 1960 en donde entra a un proceso de eliminación gradual, inclusive de abolición, con la

${ }^{8}$ La Reforma Agraria constituye un proceso de cambio gradual y ordenado de la estructura agraria en sus aspectos económico, cultural, social y político, por medio de operaciones planificadas de afectación y redistribución de la tierra, así como de los recursos de crédito, educación y tecnología, para alcanzar los siguientes objetivos: integración nacional, transformación de las condiciones de vida del campesinado, redistribución del ingreso agrícola y organización de un nuevo sistema social de empresa de mercado. Puede leerse a Galo Viteri (2007), Gustavo Cosse (1980), Cristóbal Kay (1999) y Osvaldo Barsky (1984). 
implementación de la Reforma Agraria. Las condiciones de atraso regional llevaron al descontento del campesinado, de los sectores medios urbanos, de agrupaciones de izquierda y sindicatos educativos de Loja en la década de 1960. La coyuntura regional encuentra en la abolición del latifundio y el monopolio de la tierra los detonantes para presionar un cambio en la estructura de poder político de la provincia. A nivel regional, con el éxito de la implementación de la Reforma Agraria, las familias que otrora detentaban el poder político, ligadas al Partido Conservador y a la Iglesia católica, perdieron la capacidad de dominio político y económico de la región. Esto, se vería reforzado pocos años después, finales de la década de 1970, por los avances del proceso de modernización del Estado ecuatoriano, que permitieron el ascenso y la competencia de nuevos actores político por el acceso al poder.

El nuevo escenario, la configuración de la estructura de poder político regional en el proceso de modernización estatal del Ecuador 1979-1994

Mientras en Ecuador el Partido Conservador (PCE) inicia una sensible pérdida de su capacidad electoral, en la provincia de Loja "había ganado hasta 1978 todas las elecciones generales. Liberales ni populistas habían logrado romper con esta tradición debiendo contentarse con incursiones en determinado municipio, alcaldía o prefectura, como una eterna representación de minoría" (RAMÓN, 1983:83). 1979 es el año en el que la estructura de poder político regional sufre una transformación electoral radical en la Provincia de Loja. Así, se inicia el proceso de transformación e inclusión de otros sectores sociales al escenario electoral: asociaciones de comerciantes y clase media en ascenso y los movimientos no tradicionales. La integración de Loja, la inserción a una economía nacional, la tecnificación de la agricultura y la eficiencia de la institucionalidad pública serán los temas de disputa por la representación política y los ejes sobre los cuales se articula la nueva estructura del poder político regional.

Para las elecciones regionales de 1979, el comportamiento de la votación evidenció la pérdida de los conservadores y de los liberales (29,3\% y 10,21\% respectivamente). Mientras que los dos primeros disminuyeron, la votación del movimiento Democracia Popular fue la más alta $(31,29 \%)$. Ello podría decir que los votos conservadores y liberales se tradujeron en votos por los otros movimientos, pero esta afirmación sólo se entiende a razón de los eventos posteriores a la elección: las sequías que llevaron a la migración de mano de obra campesina y la Reforma Agraria. Con la pérdida de credibilidad de la Iglesia 
católica por la "no intervención en la llegada de las lluvias" (FAUROUX, 1983:256) y la concentración poblacional que trae la disputa por la tierra, la Izquierda y principalmente las ideas de transformación permearon en las comunidades campesinas gracias al apoyo a los intentos de modernización agropecuaria.

El movimiento Democracia Popular (DP) tras la crisis de la tenencia de la tierra hace de Predesur el medio para captar a los campesinos y pequeños comerciantes de Loja. El programa Predesur,9 utilizaría dos estrategias fundamentales para ganar adeptos: La masificación de sistemas de riego y la creación de una malla vial serían las estrategias para disminuir los impactos de las largas sequías y mejorar las condiciones de ampliación de los mercados e integración económica de los nacientes comerciantes. Como estrategia de campaña, se tradujo en una mayoría en la votación para la DP, sin embrago el programa jamás pudo desarrollarse a plenitud. La masificación de los sistemas de riego no contó con la tecnificación adecuada en épocas lluviosas y las vías tardamente se fueron abriendo paso en la árida y difícil geografía de la provincia.

Pese a lo coyuntural del proceso, sin duda las elecciones de 1979 evidencian la fractura del poder político de los conservadores en la provincia de Loja. Las nuevas agrupaciones políticas, los movimientos sociales con mayor participación en la toma de decisiones, una Reforma Agraria que permitió solventar el problema de la tenencia de tierra, la poca capacidad de la élite lojana de presentar un proyecto de desarrollo en la región, llevan a que la estructura de poder político se modifique después de 1980. Los partidos políticos como el Movimiento Popular Democrático (MPD), Concentración de Fuerzas Populares (CFP) y el partido Democracia Popular (DP), no afiliados a los partidos políticos tradicionales (Liberal y Conservador), trabajan con el campesinado en procura de acrecentar la praxis política, controlar el potencial electorado e impulsar beneficios para este grupo social. Este será el comportamiento de las dos siguientes décadas.

\section{EL RETORNO A LA DEMOCRACIA EN ECUADOR}

En 1979, mientras en Loja se experimenta el desmonte de la hegemonía conservadora, el fin de la hacienda y una nueva configuración de los actores políticos, a nivel nacional el gobierno militar, con el Plan de Reestructuración Jurídica del Estado, busca el tránsito de la dictadura a democracia. El objetivo del gobierno fue desmontar las bases sociales de los

${ }^{9}$ Predesur (Programa Regional para el Desarrollo del Sur del Ecuador) se crea en 1980 con el objetivo de generar mecanismos de apoyo para el desarrollo de la región sur del Ecuador. 
partidos tradicionales que dominaban el poder en el país impidiendo su desarrollo tanto político como social y económico. Se trataba entonces de rediseñar la relación entre el sistema político y la sociedad, bajo nuevas pautas de cultura política. Con la Constitución Política de 1979, que modifica el sistema de partidos de la Constitución de 1945, se busca corregir los vicios de nuestra todavía incipiente democracia y enfrentando los complejos problemas socioeconómicos, a partir de la idea de libertad responsable y de justicia social. De esta manera La Ley de Partidos Políticos es la apuesta a la institucionalidad bajo dos elementos: Partidos políticos estables, mediadores entre la sociedad y el Estado garantizando la coherencia ideológica y política; y la ampliación de la participación política y electoral de las organizaciones políticas a través del derecho al voto universal para todos los ecuatorianos (FREIDENBERG Y ALCÁNTARA, 2001:22). Todas las modificaciones de la Ley de Partidos Políticos para el sistema electoral entran en vigencia en 1983.

Entre 1984-1994 en la provincia de Loja, los movimientos políticos de vocación popular, de izquierda, de carácter cívico o gremial toman mayor participación en el escenario electoral tras el vacío dejado en la antigua estructura de poder regional. Durante esta década, se puede observar el incremento en la votación de éstos movimientos debido a la ampliación del sistema electoral ecuatoriano expresado en Loja después de la dictadura militar. Del mismo modo, coincide con un periodo en el cual los movimientos políticos comienzan a reestructurarse tras haber dedicado la lucha por la representación política a través de las protestas y movilizaciones. Hasta las elecciones de 1994, se configura una estructura de poder político en disputa entre el rezago de la vieja tradición bipartidista y los nuevos movimientos políticos. Ella, será la base de la estructura política de la última década.

Para presentar un análisis de lo que significó la pérdida de votación de los conservadores y la participación ampliada de movimientos políticos, se ha agrupado en tres categorías a las asociaciones políticas. En la categoría Tradicionales están el Partido Conservador, el Partido Liberal y el Partido Social Cristiano (PSC), este último aparece desde 1986. En la categoría Afiliación tradicionallo encontramos al movimiento Concentración de Fuerzas Populares (CFP), Partido Roldosista Ecuatoriano (PRE), al Frente Radical Alfarista (FRA) y a Democracia Popular (DP). Finalmente, en la categoría Izquierda agrupamos al Partido Izquierda Democrática (ID), al Movimiento Popular

\footnotetext{
${ }^{10}$ En esta categoría, agrupamos a los partidos políticos que tienen como origen la disidencia de los partidos Liberal o Conservador. No obstante, la relación programática, política e ideológica con los partidos tradicionales es nula.
} 
Democrático (MPD), al Partido Socialista y al movimiento Acción Patriótica Revolucionaria Ecuatoriana (APRE).

Gráfico No. 1. Votación por Partido Político Elecciones para Asamblea Provincial 1984-1994

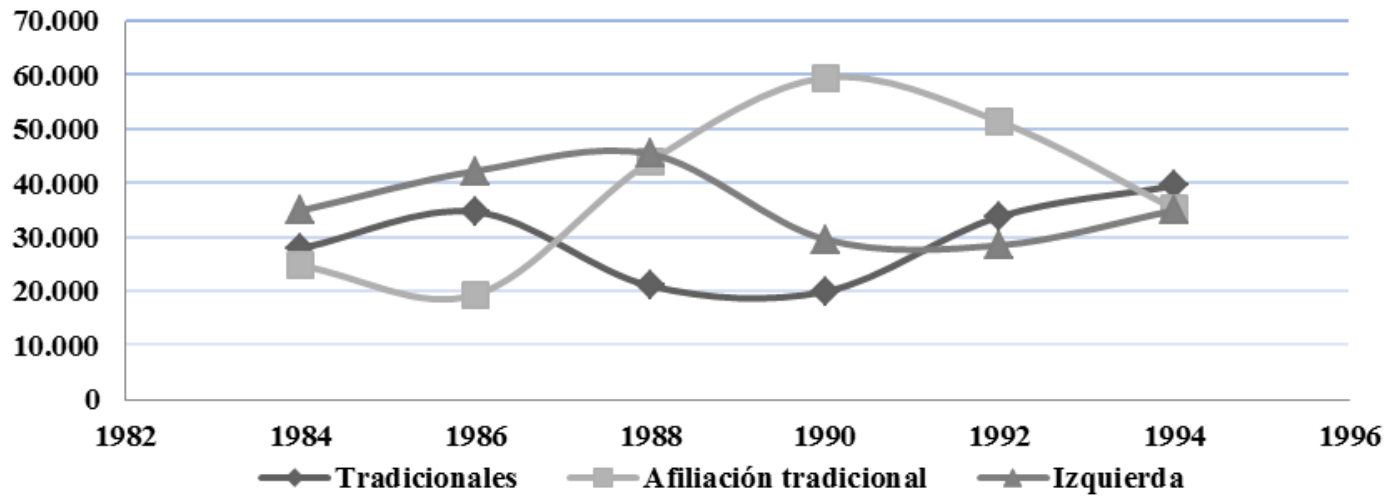

Fuente: Datos suministrados por el Consejo Nacional Electoral del Ecuador. Elaboración propia.

Se aprecia en la Gráfica No. 1 el comportamiento de la votación de las tres categorías de agrupaciones políticas en Loja. Se observa que la votación en 1984 presenta el punto de inicio de la votación de las agrupaciones con Afiliación tradicional y de Izquierda. Los de Izquierda son los que mayor votación presentan en ese año en cabeza de la ID. En segundo lugar se mantienen los partidos tradicionales (PCE y PLE). Las agrupaciones de Afiliación tradicional presentan la menor votación de las otras dos categorías debido al poco tiempo de formación de la mayoría de las agrupaciones política y las nuevas apuestas para la competencia en el escenario electoral. Pese a esto, es notorio que sin mayor tiempo de anclaje en un electorado tan disperso, la diferencia porcentual en el total de votos entre las asociaciones de Izquierda y los Tradicionales es tan sólo de 3,6\%.

El comportamiento electoral de las agrupaciones políticas en la provincia de Loja entre 1984 y 1996 como un sistema de pluralismo extremo "caracterizado por la fragmentación de partidos políticos y la poca implementación de los partidos en la sociedad" (Pachano, 2008:12). Ello, llevó a que los partidos políticos se agruparan electoralmente y buscaran en las provincias el capital electoral tras la poca coherencia entre la política nacional y la regional. Esta condición, será más evidente en el periodo 1996-2013 en el cual los partidos se refuerzan a partir de relaciones más cercanas con lo regional. En Loja, las agrupaciones políticas dependerán de figuras y de capital electoral lojano para acceder al poder.

Con el retorno de la democracia en el Ecuador tras la Constitución de 1979 y las reformas al sistema de partidos políticos, la participación electoral de la provincia se 
atomiza en organizaciones de carácter independiente y de afiliación tradicional. Las luchas por la tierra, por la educación pública, las alianzas comerciales y el desarrollo de la región se evidencian en la adscripción del electorado disperso de la provincia. Los efectos de la eliminación del sistema de dominación hacendatario en la Provincia y la legislación del sistema de partidos del Ecuador, le significó la pérdida del control político al Partido Conservador y el auge de agrupaciones políticas entre 1984 y 1996 que discutieron el desarrollo de la provincia e intentaron captar la atención de una población empobrecida ${ }^{11}$ que encontraba en el sector agrícola, el comercio y la migración interna la respuesta al atraso de la región.

En este periodo, la estructura de poder político regional recayó sobre agrupaciones ideológicamente complementarias. Por un lado, las agrupaciones políticas de izquierda en cabeza del Partido Izquierda Democrática (ID) y el Movimiento Popular Democrático (MPD). Por su parte, los partidos de afiliación tradicional, nacidos de conservadurismo y liberalismo lojano, Democracia Popular (DP) y Concentración de Fuerzas Populares (CFP) mantienen cuota de participación y representación en la configuración del poder político. Ello, permite colegir que entre la década de 1984 y 1994 el poder político estuvo en manos de partidos no adscritos a los tradicionales, todos ellos bajo las banderas de la reducción de la desigualdad en la región y su desarrollo económico.

\section{ENTRE LA INESTABILIDAD Y EL CAMBIO POLÍTICO. LA CONSOLIDACIÓN DE LA ESTRUCTURA DE PODER POLÍTICO REGIONAL EN LOJA ENTRE 1996-2013}

Luego de 20 años de la formulación de la Constitución Política de 1979, con la cual se estipula la Ley de partidos políticos en el Ecuador y la reciente crisis institucional de 1997 que llevó a una recesión económica y la posterior inestabilidad del Estado para mantener el orden político, se convoca a una consulta popular que desemboca en la Asamblea Constituyente que reformaría la legislación electoral. El nuevo escenario partidista queda regulador por la Ley, cuyos elementos centrales son la introducción de la revocatoria del mandato, la limitación en el gasto de las campañas y el nuevo sistema de nombramiento de los miembros del Tribunal Electoral. El triunfo más relevante es el reconocimiento al derecho de las agrupaciones independientes apoyadas por partidos políticos o por un

\footnotetext{
${ }^{11}$ La pobreza en la provincia de Loja entre 1990 y 1995 es de 0,74. Es decir, que 74 personas de cada 100 en Loja se encontraba en condición de pobreza.
} 
determinado número de ciudadanos. Mientras la economía busca estabilizarse y el modelo neoliberal toma fuerza, los movimientos sociales y la movilización urbana y rural, opuestas al neoliberalismo, crecen cuantitativa y cualitativamente.

Tabla No. 1. Votación por Partido Politico

Elecciones para Asamblea Provincial 1996-2013 Provincia de Loja

\begin{tabular}{|c|c|c|c|c|c|c|c|c|}
\hline Sigla & Partido & 1996 & 1997 & 2002 & 2006 & 2007 & 2009 & 2013 \\
\hline MTSI & $\begin{array}{l}\text { Transformación Social } \\
\text { Independiente }\end{array}$ & & 35.024 & & & & & \\
\hline FRA & Frente Radical Alfarista & & 31.095 & & & & & \\
\hline MUPP & $\begin{array}{l}\text { Movimiento Unidad Plurinacional } \\
\text { Pachakutik - Nuevo País }\end{array}$ & & 16.403 & 15.568 & 10.758 & & & \\
\hline PL & Partido Libertad & & 12.838 & 4.721 & - & 3.222 & & \\
\hline UNO & Partido Unión Nacional & 7.194 & 22.337 & & & & & \\
\hline CFP & $\begin{array}{l}\text { Concentración de Fuerzas } \\
\text { Populares }\end{array}$ & $\begin{array}{c}23.32 \\
2\end{array}$ & - & 73.342 & 17.648 & & & \\
\hline ID & Partido Izquierda Democrática & 5.007 & $\begin{array}{c}45.898 \\
1\end{array}$ & $\begin{array}{l}59.587 \\
\underline{2}\end{array}$ & $\begin{array}{c}36.013 \\
\underline{3}\end{array}$ & & & \\
\hline MPD & Movimiento Popular Democrático & 3.364 & 12.119 & 9.232 & 3.940 & 13.551 & 19.631 & $50.048^{4}$ \\
\hline PRE & Partido Roldosista Ecuatoriano & $\begin{array}{c}30.88 \\
1\end{array}$ & 22.595 & 44.074 & $\begin{array}{l}25.211 \\
\underline{5}\end{array}$ & 3.246 & - & 11.025 \\
\hline PSC & Partido Social Cristiano & $\begin{array}{c}21.95 \\
3\end{array}$ & 49.403 & 74.685 & 30.139 & 10.900 & & \\
\hline PSP & Partido Sociedad Patriótica & 1.366 & - & 42.598 & 12.703 & 13.462 & 9.167 & 30.462 \\
\hline PRIAN & $\begin{array}{l}\text { Renovador Institucional Acción } \\
\text { Nacional }\end{array}$ & & & 30.446 & 31.654 & 9.948 & 17.784 & 47.056 \\
\hline PS FA & Partido Socialista - Frente Amplio & 1.099 & 6.374 & 10.804 & - & $4.334 \underline{6}$ & 16.171 & \\
\hline PLRE & $\begin{array}{l}\text { Partido Liberal Radical } \\
\text { Ecuatoriano }\end{array}$ & $\begin{array}{l}3.781 \\
\quad 7\end{array}$ & - & 12.211 & & & & \\
\hline UDC & Unión Democrática Cristiana & $\begin{array}{c}19.17 \\
2\end{array}$ & - & 45.811 & 26.594 & 5.636 & & \\
\hline ARE & Acción Regional por la Equidad & & & & 46.036 & 12.651 & $25.477 \underline{8}$ & 124.412 \\
\hline MPAIS & $\begin{array}{l}\text { Movimiento Patria Altiva I } \\
\text { Soberana }\end{array}$ & & & & & 138.440 & 72.653 & 249.994 \\
\hline $\mathrm{CC}$ & $\begin{array}{l}\text { Movimiento Conciencia } \\
\text { Ciudadana }\end{array}$ & & & & & & 29.447 & - \\
\hline CREO & $\begin{array}{l}\text { Movimiento Creando } \\
\text { Oportunidades }\end{array}$ & & & & & & & 120.561 \\
\hline SUMA & $\begin{array}{l}\text { Movimiento Sociedad Unida Más } \\
\text { Acción }\end{array}$ & & & & & & & 16.909 \\
\hline $\begin{array}{l}\text { AVANZ } \\
\text { A }\end{array}$ & Partido Avanza & & & & & & & 41.073 \\
\hline CUP & $\begin{array}{l}\text { Convocatoria por la Unidad } \\
\text { Provincial }\end{array}$ & & & & & & & 64.880 \\
\hline
\end{tabular}

Fuente: Datos suministrados por el Consejo Nacional Electoral Ecuador. Elaboración propia

Con una población movilizándose, una crisis económica por resolver y los niveles de corrupción ampliamente visibles "El procesamiento de los conflictos no se realizó en el sistema político, sino directamente en el Estado. Nuevamente, los partidos políticos habían ignorado su papel de intermediación entre la sociedad y el sistema político" (SALAZAR, 2010:10). En este contexto, en el que los partidos políticos presentan una crisis de legitimidad y un agotamiento de oferta política a razón de la inoperancia legislativa, las 
agrupaciones políticas entran a competir por el poder y por la transformación del desestabilizado Estado. Las nuevas agrupaciones, enfrentadas a las viejas estructuras políticas compiten por el poder en un amplio sistema de partidos políticos bajo una fórmula por votación mayoritaria entre 1979 y 1998 y en adelante en un sistema proporcional. En la provincia de Loja, la competencia por las curules a la Asamblea evidencia la dinámica nacional. En la Tabla No. 1 se observa la amplia presencia de movimientos y partidos políticos entre 1996 y 2013 a diferencia de lo poco atomizado del periodo 1984-1994.

Las agrupaciones políticas que se presentan a las elecciones buscan crear alianzas electorales en Loja para fortalecerse internamente y cautivar a un electorado con mayores expectativas políticas para el desarrollo de la región. Si bien, la economía nacional es un tema recurrente en los ejes programáticos de los partidos, debido a la poca relación de Loja con la economía capital, sigue siendo el tema del atraso económico y la falta de presupuesto para inversión social. Es de resaltar que los partidos Izquierda Democrática (ID) y el Movimiento Popular Democrático (MPD) mantienen el mayor de los votos en el total del periodo 1996-2013. Ello, denota la tendencia del electoral de seguir apoyando a partidos no ligados al tradicionalismo. De igual manera, el Movimiento Patria Altiva I Soberana (MPAIS) y Acción Regional por la Equidad (ARE) presentan una votación significativa después de los de Izquierda. De ellos, se pude decir que tiene una votación importante basada en personajes políticos fuertes, uno a nivel nacional como el presidente Rafael Correa y otro por Bolívar Castillo, una figura de importancia para la política lojana.

Los partidos tradicionales, pierden importancia en Loja tras las nuevas agrupaciones en competencia. El conservadurismo se refuerza con el Partido Social Cristiano (PSC) y el liberalismo bajo el Partido Liberal Radical Ecuatoriano, pero con una votación mínima. La votación de las demás agrupaciones se mantiene estable, con una leve representación electoral, pero sin curules para la provincia. En el periodo 1996 - 2013, la estructura de poder político regional mantiene una estable relación en los primeros años de este periodo. Finalizando la década de 1990, las crisis económicas nacionales que se evidenciaron en la provincia por las restricciones económicas con Perú, las movilizaciones sociales y el intento por modernizar al Estado y tramitar las demandas sociales con la Constitución de 1998 llevaron a que se configurara un nuevo escenario de poder político regional. Tras una pérdida de legitimidad de los partidos políticos, el personalismo en la política es el nuevo elemento configurador de las elecciones. Alianza País, ARE y el MPD encuentran en sus 
candidatos los líderes que cohesionan las demandas de un lectorado disperso, que sigue a la espera el desarrollo económico de la provincia. De esta manera, será el personalismo político la manera más efectiva de apropiarse de los espacios de representación electoral. Este personalismo político, basado en la vieja estructura de dominación, es la expresión de la estructura de poder político regional de la provincia de Loja.

\section{LA ESTRUCTURA DE PODER POLÍTICO REGIONAL DE LA PROVINCIA}

\section{DE LOJA}

Las trayectorias políticas permiten entender cómo se ha configurado el poder político regional y por ende, definir el perfil de la estructura de poder regional. Están integradas por el capital político, que se traduce en la acumulación de recursos social, económico y electoral; y determinan, en manos de quién, está el control de los recursos estatales y las acciones políticas. De esta manera, se propone la construcción de un modelo el cual, cuantifica a manera de indicador, los alcances obtenidos por las trayectorias. El capital político obtenido por la acumulación de recurso social, económico y electoral, permite caracterizar una trayectoria política. El recurso social cualifica los perfiles, las cualidades personales y de dirigencia necesarios para pertenecer a una estructura de poder político. 
Tabla No. 2. Capital Político

Elecciones para Asamblea Provincial 1984-2013 Provincia de Loja

\begin{tabular}{|c|c|c|c|c|}
\hline \multirow{2}{*}{ Candidatos } & \multicolumn{3}{|c|}{ Recurso electoral } & \multirow{2}{*}{$\begin{array}{l}\begin{array}{c}\text { Capital } \\
\text { político }\end{array} \\
\mathrm{CP}\end{array}$} \\
\hline & $E E$ & $E \boldsymbol{V}$ & $C L$ & \\
\hline José Bolívar Castillo Vivanco & 1,00 & 0,98 & 1,00 & 0,99 \\
\hline José Picoita & 1,00 & 0,98 & 1,00 & 0,99 \\
\hline Edgar Garrido & 1,00 & 0,80 & 1,00 & 0,93 \\
\hline Pio Oswaldo Cueva & 1,00 & 0,80 & 1,00 & 0,93 \\
\hline Eloy Torres & 1,00 & 0,80 & 1,00 & 0,93 \\
\hline Rafael Antonio Dávila Egüez & 0,75 & 0,84 & 1,00 & 0,86 \\
\hline Fausto Moreno Sánchez & 0,75 & 0,81 & 1,00 & 0,85 \\
\hline $\begin{array}{l}\text { Jorge Cristóbal Montero } \\
\text { Rodríguez }\end{array}$ & 0,75 & 0,80 & 1,00 & 0,85 \\
\hline $\begin{array}{l}\text { José Benigno Carrión } \\
\text { Maldonado }\end{array}$ & 0,71 & 0,82 & 1,00 & 0,84 \\
\hline Miryam González Serrano & 0,50 & 0,79 & 1,00 & 0,76 \\
\hline $\begin{array}{l}\text { Martha Cecilia Machado } \\
\text { Paladines }\end{array}$ & 0,50 & 0,78 & 1,00 & 0,76 \\
\hline Ana Moser & 0,50 & 0,62 & 1,00 & 0,71 \\
\hline Mao Bolívar Moreno Lara & 0,33 & 0,73 & 1,00 & 0,69 \\
\hline Jorge Bustamante & 1,00 & 0,00 & 1,00 & 0,67 \\
\hline Duman Rey Trelles & 0,50 & 0,80 & 0,50 & 0,60 \\
\hline $\begin{array}{l}\text { Freddy Gonzalo Bravo } \\
\text { Bravo }\end{array}$ & 0,20 & 0,54 & 1,00 & 0,58 \\
\hline Guillermo Lennin Falconi & 0,00 & 0,70 & 1,00 & 0,57 \\
\hline Raúl Auquilla Ortega & 0,00 & 0,70 & 1,00 & 0,57 \\
\hline $\begin{array}{l}\text { Soledad Mireya Aguirre } \\
\text { Riofrio }\end{array}$ & 0,00 & 0,62 & 1,00 & 0,54 \\
\hline $\begin{array}{l}\text { Elva Mariana Rodríguez } \\
\text { Villavicencio }\end{array}$ & 0,00 & 0,56 & 1,00 & 0,52 \\
\hline Sandra Jiménez & 0,00 & 0,44 & 1,00 & 0,48 \\
\hline $\begin{array}{l}\text { Eduardo Alejandro Armijos } \\
\text { Gutiérrez }\end{array}$ & 0,00 & 0,43 & 1,00 & 0,48 \\
\hline $\begin{array}{l}\text { Cesar Augusto Correa } \\
\text { Jaramillo }\end{array}$ & 0,00 & 0,42 & 1,00 & 0,47 \\
\hline Cesar Antonio León Aguirre & 0,00 & 0,68 & 0,50 & 0,39 \\
\hline Willian Ludeña Celi & 0,00 & 0,16 & 1,00 & 0,39 \\
\hline Judith Rodríguez Torres & 0,00 & 0,15 & 1,00 & 0,38 \\
\hline Ramiro Villamagua Carrión & 0,00 & 0,13 & 1,00 & 0,38 \\
\hline Eduardo Aguirre Valladares & 0,00 & 0,12 & 1,00 & 0,37 \\
\hline Ligia Isabel Rodríguez Lima & 0,00 & 0,12 & 1,00 & 0,37 \\
\hline Juan Carlos Ríos Espinoza & 0,00 & 0,09 & 1,00 & 0,36 \\
\hline Flavio Armijos & 0,00 & 0,08 & 1,00 & 0,36 \\
\hline Gioconda Tapia & 0,00 & 0,05 & 1,00 & 0,35 \\
\hline Nela Guzmán & 0,00 & 0,05 & 1,00 & 0,35 \\
\hline Mariana de Jesús Román & 0,00 & 0,03 & 1,00 & 0,34 \\
\hline $\begin{array}{l}\text { Luis Fernando Sarango } \\
\text { Macas }\end{array}$ & 0,00 & 0,30 & 0,50 & 0,27 \\
\hline
\end{tabular}

Fuente: Elaboración propia. 
El capital político, a partir de los componentes del recurso electoral son calculados a partir de modelos de medición y sus valores permiten determinar el grado de recurso electoral de las trayectorias. En ese sentido, el capital político acumulado a partir del recurso electoral es igual al promedio de los valores de cada componente de este recurso, más el valor cualitativo del recurso social. Su ponderación da como resultado un valor entre 1,0 y 0,0 donde los valores que se aproximen a 1 representan mayor capital político de las trayectorias

Recurso electoral: Este recurso permite caracterizar el comportamiento electoral de una trayectoria política a partir de tres dimensiones: La composición de las listas, la efectividad en los procesos electorales y la eficiencia electoral. Cada uno, en la provincia de Loja, presenta el siguiente comportamiento:

1. Composición de las listas (CL): Este componente da cuenta del número de veces que un candidato se postuló por una agrupación política determinada y las veces que su nombre encabezó dicha lista para afrontar un proceso electoral. Se consideran todos los candidatos que se postularon los comicios de asamblea provincial durante el periodo 19842013. Las postulaciones que encabezan las listas se representan con el número 1 ó 0, donde 1 significa lista encabezada por un actor político y 0 una posición distinta dentro de una plancha electoral. El valor en la casilla CL representa el nivel de adquisición en este componente. Toma los valores menores o iguales a 1 y los pondera. Entre más cerca del 1,00 se encuentre un candidato mayor adquisición de recurso electoral presenta en toda su trayectoria política.

Se puede observar que aquellos candidatos que presentan mayor índice de Composición de las Listas fueron miembros directivos de las distintas agrupaciones políticas entre 1984 y 1996. La mayoría de los candidatos obtiene valores de 1,00; siendo sólo 4 candidatos los que obtuvieron un escaño gracias a la amplia votación de quienes encabezaron las listas. Por su parte, se observa que después de 1997, los candidatos que se postulan presentan el número 1, que equivale a encabezar las listas. Ello, producto de la modificación a la Ley electoral en donde las postulaciones son personalizadas y la adscripción a un partido político es sólo una necesidad legal.

2. Efectividad electoral (EE): Este componente, da cuenta del número efectivo de éxitos electorales para Asamblea Provincial. Para ello, se consideran aquellos candidatos que se postulan en más de dos ocasiones durante todo el periodo y se ponderan las veces en las que se postulan y las veces efectivas que obtienen escaños. En la Tabla No. 2 se 
observa el total de candidatos que cumplen con esta condición. Las postulaciones se representan con el número 1 ó 0 , donde 1 significa escaño obtenido y 0 una derrota electoral. El valor en la casilla EE representa el nivel de adquisición en este recurso. Toma los valores menores o iguales a 1 y se ponderan. Entre más cerca del 1,00 se encuentre un candidato mayor adquisición de recurso electoral presenta en toda su trayectoria política.

Resalta del comportamiento electoral en la provincia de Loja los pocos candidatos que obtienen un escaño en cada año en el que participan en los comicios. Ello, demuestra una concentración de candidatos para la Asamblea Nacional y la poca movilidad de los partidos políticos para renovar a sus candidatos. Sólo 6 candidatos (José Bolívar Castillo, Pio Oswaldo Cueva, Eloy Torres, Edgar Garrido, José Picoita y Jorge Bustamante) han tenido éxito en todos los comicios a los que se presentaron. Este comportamiento se ve reflejado en los valores de eficiencia electoral con 1. Este grupo se ha caracterizado por tener una relación cercana con los electores tras su trabajo en entidades gubernamentales y de nivel ejecutivo, ganando reconocimiento social y político en la región y de contar, o haber contado, con cargos de dirección regional de los partidos políticos a los que se postularon.

3. Eficiencia electoral (EV): Este recurso da cuenta de la concentración electoral de un candidato. Se pondera la votación total obtenida en cada año para estimar la pérdida o ganancia de votos, independientemente del partido político al que está adscrito. Es de resaltar que en la Provincia de Loja que existe un concentración relativa en todos los candidatos que se postularon más de una vez a los comicios en todo el periodo de estudio. Los valores más cercanos a 1 son los de mayor concentración electoral, que traduce que la votación obtenida año por año. En la provincia de Loja, el Partido Conservador obtuvo la mayoría de los escaños hasta 1979. Entre 1984 y 1997 los partidos Concentración de Fuerzas Populares (CFP), el Partido Roldosista Ecuatoriano (PRE), Democracia Popular (DP), el Partido de Izquierda Democrática (ID) y el Movimiento Popular Democrático (MPD) contaron con participación en la Asamblea Nacional. Con el nuevo sistema de listas abiertas, la competencia por un escaño se basó en buscar el mayor número de votos independientemente del trabajo partidista. De ahí, que el componente de eficiencia electoral permita determinar la importancia del trabajo individual de cada candidato. Se observa, que la mayoría de los candidatos tienen niveles de efectividad electoral por encima del 0.50 lo que permite colegir que la concentración de los votos es condición propia de las trayectorias políticas más que del trabajo de los partidos político. Así, se asiste desde las 
elecciones de 1997 al personalismo en la política, en donde el éxito electoral es producto del trabajo de cada candidato, de las relaciones de clientela y proselitismo que se puedan entablar durante una trayectoria política.

A partir del capital electoral, se propone crear una tipología según la cual, entre más cercano sea el valor a 1,0 y menor a 0,8 la trayectoria se ha consolidado y tiene un control general de la actividad política de la provincia. Los valores entre 0,79 y 0,61 determinan una trayectoria ligada y emergente a un jefe de clientela, con un electorado estable, aunque con poca capacidad para controlarlo, y con representación en la Asamblea Nacional; y los valores menores a 0,6 expresan una trayectoria política frágil o en consolidación, con poca capacidad de cohesión del electorado y dependiente de un jefe político que garantice algún éxito en las urnas o un cargo burocrático.

En la Tabla No. 2 se observa que las trayectorias se caracterizan en tres grupos. Cada grupo, cuenta con atributos axiales que les son propios y la ubicación de cada trayectoria en un grupo depende del alcance que cada actor político haya obtenido a lo largo de su ejercicio político. El primero es el grupo al que llamamos Notables. Está compuesto de todos los profesionales políticos que cumplen los atributos expuestos en cada recurso del poder político. Ellos, son políticos profesionales que alcanzan, durante su ejercicio legislativo, una acumulación suficiente de capital político que les permite determinar las acciones políticas, tener capacidad de injerencia en las instituciones estatales de nivel regional, el reconocimiento del electorado que, sin importar las etiquetas partidistas, le es leal, y controlar, promover y disponer de sus clientelas. En suma, configuran de manera determinante el poder político regional.

El segundo grupo está integrado por los políticos profesionales Emergentes. En él están todos aquellos que cumplen con los atributos de un miembro de los Notables, pero obtienen valores medios en cada uno de los recursos, lo que dificulta la acumulación de capital político suficiente para determinar su participación en la estructura de poder político regional. Es decir, debido a la insuficiente adquisición de capital político, sus acciones como políticos profesionales se limitan a influir en las decisiones políticas, tener alguna representación en las instituciones estatales, principalmente en las regionales. Poseen un electorado débil e inestable producto de la baja capacidad de cohesión que les lleva a disponer de él de manera coyuntural pues está íntimamente ligado a la figura personal del político profesional y los cargos que, en su trabajo proselitista, pueden proveer. En términos generales, este grupo tiene la capacidad de incidir en la configuración del poder político regional. 
El tercer grupo está compuesto por los Dependientes. Son aquellos actores políticos que no alcanzaron a acumular significativamente capital político, lo que lleva a que la injerencia en las decisiones y la representación política se haga efectiva bajo el amparo de los profesionales políticos con una trayectoria exitosa, principalmente, los que pertenecen al grupo de los Notables. Pese a ello, este grupo permite el mantenimiento de la estructura del poder político, ya que son ellos quienes trabajan y cumplen funciones de articuladores entre el electorado disperso y los cargos burocráticos provinciales. En suma, este grupo está conformado por aquello políticos que pueden trabajar para el mantenimiento de una estructura de poder político, pero carecen de incidencia en la política regional. De ahí, que sólo tengan posibilidad de permanecer, pero sin determinar cambios sustanciales en ella.

Esta tipología nos permite entender la configuración del poder político regional como una estructura donde en la base están los dependientes, aquellos que reproducen y trabajan en función de mantener y garantizar el control del poder. Los emergentes se ubican en el centro de esta estructura, y son quienes influyen y tiene injerencia en el control del poder, y en la cima, se encuentran los notables, los cuales controlan el poder y determinan las actividades políticas del departamento. En ese sentido, el poder político se configura por la capacidad que las trayectorias políticas tienen para reproducir, influir y determinar, el nivel de control de poder político, la toma de decisiones y la implementación de políticas públicas.

El grupo de los Notables, resulta ser el de más interés por lo variopinto de su composición. Está integrado por José Bolívar Castillo Vivanco, José Picoita, Edgar Garrido, Pio Oswaldo Cueva, Eloy Torres, Rafael Antonio Dávila Egüez, Fausto Moreno Sánchez, Jorge Cristóbal Montero Rodríguez y José Benigno Carrión Maldonado. El trabajo electoral y la trayectoria política de cada uno, permite configurar la estructura de poder político bajo un escenario, que escapa al sistema de dominación de la hacienda, que se caracteriza por la ausencia de un proyecto político de región. Son varios los partidos políticos por los cuales se adscriben estos candidatos, lo que demuestra que, más allá de ser un sistema regional participativo, carece de un proyecto de desarrollo articulado por el nivel nacional. La excepción, Alianza País, pareciera configurar una apuesta por la articulación nacionalregional, pero la información en el periodo 2006-2013 en Loja denota el alto nivel burocrático de la provincia y la dependencia económica de ésta no garantizando la expresión más general del proyecto nacional más allá de las políticas nacionales. Los otros dos grupos (Emergentes y Dependientes) hacen parte de esta estructura de poder pero su 
participación en ella, es de reproducción más no de modificación. De esta manera, se puede colegir que el regionalismo se convirtió, entonces, en la expresión de la estructura de poder político entre 1984 y 2013.

\section{A MODO DE CONCLUSIÓN}

Se puede observar, que si bien los cambios sociales y las modificaciones en el sistema político establecieron nuevas reglas de juego electoral, en la provincia las viejas prácticas heredadas de la hacienda y el Partido Conservador se perdieron bajo la aparición de nuevos actores y modificaciones legales para la participación electoral. Sin embargo, la asignación de cargos burocráticos como intermediación clientelista y la organización de las asociaciones políticas bajo estructura de base, siguen teniendo relevancia en la nueva estructura de poder. Los actores políticos tienen que trabajar para posicionarse en el escenario político y electoral a partir de recursos sociales. "Una de la más importantes armas en esa lucha por una posición fuerte dentro del campo político es la biografía personal" (Collovald, 1998:29). El trabajo en la provincia, sumado a las alianzas y el capital que se logre acumular, define la trayectoria política de un grupo de profesionales políticos que determinan cómo se controla el poder político. De esta manera, el regionalismo juega un papel importante tras los intentos fallidos de está élite por articular la política regional con la nacional.

Después de la abolición del sistema de dominación hacendal y el retorno de la democracia, se puede observar que no existen grandes jefes políticos en la región, pues los medios de reproducción económica no se encuentran concentrados y los partidos políticos se han disputado el comportamiento electoral en repetidas oportunidades, haciendo de la estructura de poder político regional una estructura fragmentada. Bajo esta agrupación, es posible identificar las trayectorias políticas de quienes han detentado el poder político en la provincia de Loja. Es de resaltar que las trayectorias políticas de los miembros del grupo de Notables han determinado la estructura de poder político de la región. El nuevo líder, que nace del proceso de abolición del latifundio, no está ligado precisamente al prestigio de la tierra y los medios de producción. Esta figura todavía existe, pero no es de dominio general. Toda estructura de poder determina, según su forma, la manera como el propio poder se reparte en el grupo social. Los actores políticos usaron las premodernas prácticas políticas para profesionalizar, a través del clientelismo adecuado al nuevo sistema, el trabajo electoral. La acumulación de capital político, materializado en votos y control de recursos estatales, constituyeron la base para que la labor de la política se profesionalizara. 


\section{BIBLIOGRAFÍA}

ALCÁNTARA, M. (2012). El oficio de político. Madrid: Tecno.

ALCÁNTARA, M. (2006). Politicos y politica en América Latina. Madrid: Siglo XXI-Fundación Carolina.

ALMOND, G. y VERBA, S. (1991). "La Cultura Política". En Diez textos básicos de ciencia política, Gabriel Almond et al.: 171. Barcelona: Ariel Editores.

AUYERO, J. (2004). Clientelismo Político: las caras ocultas. Buenos Aires: Editorial Capital Intelectual.

BARSKY, O. (1978). Iniciativa terrateniente en el pasaje de hacienda a empresa capitalista: el caso de la sierra ecuatoriana (1959-1964). Disertación doctoral, Pontificia Universidad Católica del Ecuador - Consejo Latinoamericano de Ciencias Sociales.

BURBANO, F. (1997). El fantasma del populismo. Caracas: Nueva Sociedad.

COLLOVALD, A. (1999). Jacques Chirac: Biografía de un heredero de historias. Paris: Berlín.

CORNEJO CASTRO, B. (1993). La integración fronteriza ecuatoriano-peruana y sus perspectivas. Quito: CORDES.

COSSE, G. (1980). "Reflexiones acerca del Estado, el proceso político y la política agraria en el caso ecuatoriano 1964-1977". En Estudios Rurales Latinoamericanos, CLACSO (Comp.): 51. Bogotá: Publicación cerrada.

CUEVA, A. (1973). Elproceso de dominación politica en Ecuador. Quito: Editorial Voluntad.

DÍAZ, E. (1986). El clientelismo en Colombia. Bogotá: Ancora editores.

FAUROUX, E. (1983). Distribución de la población en la provincia e Loja y su evolución entre 1950 y 1974. Cultura: Revista del Banco Central del Ecuador número 15: 255.

FREIDENBERG, F. y ALCÁNTARA, M. (2001). Los dueños del poder: los partidos políticos en Ecuador (1978-2000). Quito: Flacso - sede Ecuador.

GALARZA, J. (1976). Los campesinos de Loja y Zamora. Quito: Soltierra.

GARCÍA, B. (1991). "Regionalismo y modernas tendencias politicas". En La cuestión regional y el poder, Rafael Quintero (Comp.): 161-206. Quito: Corporación Editora Nacional.

GUERRERO, A. (1975). La hacienda precapitalista y la clase terrateniente en América Latina y su inserción en el modo de producción capitalista. Quito: Escuela de Sociología - Universidad Central del Ecuador.

GUERRERO, T. (2005). El reto bistórico de Loja. Loja: Editorial Universidad Técnica Particular de Loja.

HURTADO, O. (1993). Elpoder político en el Ecuador. Quito. Letraviva Planeta.

IBARRA CRESPO, H. (2002). Origen y decadencia del gamonalismo en la sierra ecuatoriana. Sevilla: Escuela de Estudios Hispano-Americanos.

JARAMILLO ALVARADO, P. (1974). Crónicas y documentos al margen de la bistoria de Loja y su provincia. Loja: Editorial del Núcleo del Guayas de la Casa de la Cultura Ecuatoriana. 
LEAL B. y DÁVILA, A. (1991). Clientelismo: el sistema politico y su expresión regional. Bogotá: Tercer Mundo Editores.

LECOQ, P. (1983). El periodo de desarrollo regional en el sur de la provincia de Loja. Cultura: Revista del Banco Central del Ecuador número 15: 73.

KAY, C. (1999). "Mirando hacia atrás: el tiempo de las reformas agrarias". Revista Envío. Número 209. Disponible en http://www.envio.org.ni/articulo/958 (visitado en junio 15 de 2013).

MILLS, C. W. (1957). La élite del poder. México: Fondo de Cultura Económica.

MOSCA, G. (1984). La clase política. México: Fondo de Cultura Económica.

ORTIZ SARMIENTO, C. (1986). Estado y subversión el Colombia. La violencia en el Quindío en los años 50. Bogotá: Fondo Editorial Cerec - Universidad Nacional de Colombia.

PACHANO, S. (2008). Calidad de la democracia y colapso del sistema de partidos en Ecuador. Quito: Flacso - sede Ecuador.

PANEBIANCO, A. (1982). Modelos de partido. Madrid: Alianza Editorial.

PUTNAM, R. (1976). The Comparative Study of Political Elites. New Jersey: Englewood Cliffs, N.J - Prentice-Hall.

QUINTERO, R. (1991). La cuestión regionaly el poder. Quito: Corporación Editora Nacional.

RAMÓN VALERAZO, G. (1983). La nueva bistoria de Loja. Quito: (s.e).

ROJAS GUERRA, J. M. y CASTILLO, L. C. (1991). Poder local y recomposición campesina. Cali: Fondo DRI-CIDSE - Universidad del Valle Leal Buitrago (1991),

SALAZAR, O. (2010). La reforma política y la Constitución de 1998. Disertación maestría en Estudios Políticos, Flacso - sede Ecuador.

SLAB, A. (2002). Ruling Passions. Political Offices and Democratic Ethics. Princeton: Princeton University Press.

SARTORI, G. (1992). Elementos de teoría política. Madrid: Alianza Universidad

VITERI, G. (2007). "La Reforma Agraria en el Ecuador". Disponible en www.eumed.net/libros/2007b/298/, visitado en junio 13 de 2013.

WEBER, M. (1967). El político y el cientifico. Madrid: Alianza Editorial. (1977). Estructuras del poder. Buenos Aires: Editorial Pleyade. 